\title{
T1p Hip Cartilage Mapping in Assessing Patients With Cam Morphology: How Can We Optimize the Regions of Interest?
}

\author{
Helen Anwander MD, Kawan S. Rakhra MD, Gerd Melkus PhD, \\ Paul E. Beaulé MD
}

Published online: 9 August 2016

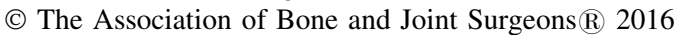

\begin{abstract}
Background T1 $\rho$ MRI has been shown feasible to detect the biochemical status of hip cartilage, but various regionof-interest strategies have been used, compromising the reproducibility and comparability between different institutions and studies.

Questions/purposes The purposes of this study were (1) to determine representative regions of interest (ROIs) for cartilage T1 $\rho$ mapping in hips with a cam deformity; and (2) to assess intra- and interobserver reliability for cartilage T1 $\rho$ mapping in hips with a cam deformity.
\end{abstract}

One of the authors (HA) has received funding from the Swiss National Science Foundation. One of the authors (PEB) has received funding from the Canadian Institutes of Health Research (97778). All ICMJE Conflict of Interest Forms for authors and Clinical Orthopaedics and Related Research ${ }^{\circledR}$ editors and board members are on file with the publication and can be viewed on request.

Clinical Orthopaedics and Related Research ${ }^{\circledR}$ neither advocates nor endorses the use of any treatment, drug, or device. Readers are encouraged to always seek additional information, including FDAapproval status, of any drug or device prior to clinical use.

Each author certifies that his or her institution approved the human protocol for this investigation, that all investigations were conducted in conformity with ethical principles of research, and that informed consent for participation in the study was obtained.

This work was performed at The Ottawa Hospital, Ottawa, Canada.

H. Anwander, P. E. Beaulé ( $\square)$

Division of Orthopaedic Surgery, The Ottawa Hospital,

501 Smyth Road, Ottawa K1H 8L6, Canada

e-mail: pbeaule@ottawahospital.on.ca

K. S. Rakhra, G. Melkus

Department of Medical Imaging, The Ottawa Hospital, Ottawa, Canada

K. S. Rakhra, G. Melkus

Department of Radiology, University of Ottawa, Ottawa, Canada
Methods The local ethics committee approved this prospective study with written informed consent obtained. Between 2010 and 2013, in 54 hips (54 patients), T1 $\rho$ 1.5T MRI was performed. Thirty-eight hips (38 patients; $89 \%$ male) with an average age of $35 \pm 7.5$ years (range, 23-51 tears) were diagnosed with a cam deformity; 16 hips (16 patients; $87 \%$ male) with an average age of $34 \pm 7$ years (range, 23-47 years) were included in the control group. Of the 38 patients with a cam deformity, 20 were pain-free and 18 symptomatic patients underwent surgery after 6 months of failed nonsurgical management of antiinflammatories and physical therapy. Exclusion criteria were radiologic sings of osteoarthritis with Tönnis Grade 2 or higher as well as previous hip surgery. Three region-of-interest (ROI) selections were analyzed: Method 1: as a whole; Method 2: as 36 to 54 small ROIs (sections of $30^{\circ}$ in the sagittal plane and $3 \mathrm{~mm}$ in the transverse plane); Method 3a: as six ROIs (sections of $90^{\circ}$ in the sagittal plane and one-third of the acetabular depth in the transverse plane: the anterosuperior and posterosuperior quadrants, divided into lateral, intermediate, and medial thirds); and Method $3 \mathrm{~b}$ : as the ratio (anterosuperior over posterosuperior quadrant). ROIs in Method 3 represent the region of macroscopic cartilage damage, described in intraoperative findings. To asses interobserver reliability, 10 patients were analyzed by two observers (HA, GM). For intraobserver reliability, 20 hip MRIs were analyzed twice by one observer (HA). To assess interscan reliability, three patients underwent two scans within a time period of 2 weeks and were analyzed twice by one observer (HA). T1 $\rho$ values were compared using Student's t test. Interclass correlation coefficient (ICC) and root mean square coefficient of variation (RMS-CV) were used to analyze intraobserver, interobserver, and interscan reliability. 
Results Patients with a cam deformity showed increased T1 $\rho$ values in the whole hip cartilage (mean: $34.0 \pm 3.8 \mathrm{~ms}$ versus $31.4 \pm 3.0 \mathrm{~ms}$; mean difference: 2.5 ; $95 \%$ confidence interval [CI], 4.7-0.4; $\mathrm{p}=0.019$; Method 1), mainly anterolateral (2), in the lateral and medial thirds of the anterosuperior quadrant (mean: $32.3 \pm 4.9$ ms versus 29.4 $\pm 4.1 \mathrm{~ms}$; mean difference: $3.0 ; 95 \%$ CI, 5.8-0.2; $\mathrm{p}=0.039$ and mean $36.5 \pm 5.6 \mathrm{~ms}$ versus $32.6 \pm 3.8 \mathrm{~ms}$; mean difference: $3.8 ; 95 \% \mathrm{CI}, 6.9-0.8 ; \mathrm{p}=0.014)$, and in the medial third of the posterosuperior quadrant (mean: $34.4 \pm$ $5.5 \mathrm{~ms}$ versus $31.1 \pm 3.9 \mathrm{~ms}$; mean difference: $3.1 ; 95 \%$ CI, 6.2-0.1; $\mathrm{p}=0.039$ ) (3a). The ratio was increased in the lateral third (mean: $1.00 \pm 0.12$ versus $0.90 \pm 0.15$; mean difference: $0.10 ; 95 \%$ CI, 0.18-0.2; p = 0.018) (3b). ICC and RMS-CV were 0.965 and $4 \%$ (intraobserver), 0.953 and $4 \%$ (interobserver), and 0.988 (all p < 0.001) and 9\% (inter-MR scan), respectively.

Conclusions Cartilage T1 $\rho$ MRI mapping in hips is feasible at $1.5 \mathrm{~T}$ with strong inter-, intraobserver, and interMR scan reliability. The six ROIs (Method 3) showed a difference of T1 $\rho$ values anterolateral quadrant, consistent with the dominant area of cartilage injury in cam femoroacetabular impingement, and antero- and posteromedial, indicating involvement of the entire hip cartilage health. The six ROIs (Method 3) have been shown feasible to assess cartilage damage in hips with a cam deformity using T1 $\rho$ MRI. We suggest applying this ROI selection for further studies using quantitative MRI for assessment of cartilage damage in hips with a cam deformity to achieve better comparability and reproducibility between different studies. The application of this ROI selection on hips with other deformities (eg, pincer deformity, developmental dysplasia of the hip, and acetabular retroversion) has to be analyzed and potentially adapted.

Level of Evidence Level III, diagnostic study.

\section{Introduction}

Cam-type femoroacetabular impingement (FAI) is a common hip deformity and major cause of osteoarthritis (OA) in young adults [10]. Detection of early-stage OA is essential to determine when best to intervene to increase the likelihood that the treatment will decrease pain and improve function [8, 28]. Conventional radiography and standard MRI are insensitive for early biochemical cartilage damage. Advanced MRI techniques have emerged for detection and quantification of biochemical changes in cartilage, even before macroscopic damage occurs. Biochemical changes in early-stage OA include loss of proteoglycan content [6]. One technique, which is sensitive to the proteoglycan content in cartilage, is delayed gadolinium-enhanced MRI of cartilage (dGEMRIC). It has been shown that dGEMRIC can serve in the evaluation of hips with dysplasia [22] or a cam deformity [4]. However, dGEMRIC requires intravenous injection of an exogenous contrast agent; other quantitative approaches for cartilage imaging that do not use contrast agents now are available, including $\mathrm{T} 1 \rho$ mapping. $\mathrm{T} 1 \rho$ relaxation time has been shown to correlate inversely with cartilage proteoglycan concentration in bovine and human cartilage samples, making it a potentially useful tool for detection of early biochemical changes in cartilage tissue occurring in the OA disease [27, 31]. Several studies have demonstrated the feasibility of $\mathrm{T} 1 \rho$ mapping to assess cartilage condition in the knee [11, 13, 21, 23] and hip [26, 29].

The pattern of cartilage damage in hips is influenced by the underlying pathology. Beck et al. [3] first described intraoperative cartilage damage in hips with cam-type FAI mainly in the anterosuperior quadrant, which is consistent with other intraoperative observations [2, 14, 20] and findings in computer simulation [30]. Although MRI mapping of cartilage in the hip has been shown to be feasible and capable to evaluate the biochemical status of cartilage in dysplasia [19, 25, 26, 29] as well as cam FAI (Table 1) [4, 7, 9, 19, 24-26, 29], the region-of-interest (ROI) selection used in terms of size and location has varied between studies. Having said that, understanding how to best define and analyze the ROIs is still evolving and is critical to ensure reproducible and comparable results between institutions and studies.

Therefore, the first aim of this study was to determine representative ROIs for cartilage $\mathrm{T} 1 \rho$ mapping in hips with a cam deformity. The second aim was to assess intra- and interobserver reliability for cartilage $\mathrm{T} 1 \rho$ mapping in hips with a cam deformity.

\section{Patients and Methods}

This prospective, comparative study was approved by the local ethics committee with informed consent obtained. Fifty-eight patients (58 hips) were enrolled; 38 asymptomatic patients were part of a previous study [12] and 20 patients with unilateral cam-type FAI were recruited in the institution. The study, including the 38 asymptomatic patients, analyzed the prevalence of cam deformity in asymptomatic volunteers. T $1 \rho$ values in these patients have not been analyzed and published previously.

Four MRIs were excluded as a result of motion artifacts. The final study group consisted of 54 hips (44\% right) in 54 patients with an average age of $35 \pm 7$ years; $88 \%$ were men (Table 2). MRIs were acquired between December 2010 and November 2013. 
Table 1. Regions of interest (ROIs) in quantitative MRI analyzing hip cartilage

\begin{tabular}{|c|c|c|c|c|c|c|c|c|c|c|c|}
\hline \multirow[t]{2}{*}{ Reference } & \multirow{2}{*}{$\begin{array}{l}\text { Region } \\
\text { (o'clock) }\end{array}$} & \multicolumn{2}{|l|}{ Zones } & \multicolumn{3}{|l|}{ Slices } & \multicolumn{2}{|c|}{$\begin{array}{l}\text { Femoral/acetabular } \\
\text { cartilage }\end{array}$} & \multirow[t]{2}{*}{ Total ROI } & \multicolumn{2}{|l|}{ MRI } \\
\hline & & Number & $\begin{array}{l}\text { Interval } \\
\left(^{\circ}\right)\end{array}$ & Number & Location & $\begin{array}{l}\text { Thickness } \\
(\mathrm{mm})\end{array}$ & Separate & Combined & & $\mathrm{T} 1 \rho$ & dGEMRIC \\
\hline Subburaj et al. [29] & 4:00-7:00 & 9 & 30 & 1 & Central & 4 & $\mathrm{x}$ & $\mathrm{x}$ & 9 & $\mathrm{x}$ & \\
\hline Rakhra et al. [25] & $3: 00-9: 00$ & 4 & 45 & 7 & Lateral $\rightarrow$ medial & 3 & & $\mathrm{x}$ & 28 & $\mathrm{x}$ & \\
\hline McGuffin et al. [19] & 3:00-9:00 & 2 & 90 & 7 & Lateral $\rightarrow$ medial & 3 & & $\mathrm{x}$ & 14 & $\mathrm{x}$ & \\
\hline Bittersohl et al. [4] & 5:00-9:00 & 8 & 30 & 2 & $1 \times$ lateral $/ 1 \times$ central & & & $\mathrm{x}$ & 16 & & $\mathrm{x}$ \\
\hline Domayer et al. [7] & $4: 00-8: 00$ & 8 & 30 & 2 & $1 \times$ lateral $/ 1 \times$ central & & & $\mathrm{x}$ & 16 & & $\mathrm{x}$ \\
\hline Pollard et al. [24] & $3: 00-12: 00$ & 1 & 90 & 1 & Lateral & 9 & & $\mathrm{x}$ & 1 & & $\mathrm{x}$ \\
\hline
\end{tabular}

The table displays studies analyzing cartilage in hips with cam morphology with advanced MRI techniques (T1 $\rho$ and dGEMRIC) using different ROIs; dGEMRIC = delayed gadolinium-enhanced MRI of cartilage.

Table 2. Demographics of the study group

\begin{tabular}{|c|c|c|c|c|}
\hline Parameters & All hips & Hips with a cam deformity & Control hips & $\mathrm{p}$ value \\
\hline Number of hips (number of subjects) & $54(54)$ & $38(38)$ & $16(16)$ & - \\
\hline Age (years) & $35 \pm 7(23-51)$ & $35 \pm 8(23-51)$ & $34 \pm 7(23-47)$ & 0.381 \\
\hline Sex ( $\%$ male $)$ & 88 & 89 & 87 & 0.582 \\
\hline Side (\% right) & 44 & 42 & 50 & 0.367 \\
\hline
\end{tabular}

The study group was divided into hips with a cam deformity and control hips; there was no difference in age, sex, or side of the included hip between; values of continuous parameters are expressed as mean \pm SD with range in parentheses.

Two groups were defined: 38 hips with a cam deformity and 16 control hips. A cam deformity was defined as an alpha angle $>51^{\circ}$ at the $3: 00$ position and/or $>60^{\circ}$ at the 1:30 position [1]. Of the 38 patients with a cam deformity, 20 were pain-free and 18 symptomatic patients underwent surgery after 6 months of failed nonsurgical management of antiinflammatories and physical therapy.

Exclusion criteria were radiologic signs of osteoarthritis with Tönnis grade of 2 or higher as well as previous hip surgery.

Between the two groups, there was no difference in age or gender (Table 2). None of the patients had an underlying hip disease, previous surgery, or radiologic signs for OA.

T1 $\rho$ imaging was performed on a 1.5-T MRI scanner (Magnetom Symphony; Siemens Medical Solutions, Erlangen, Germany) using the built-in body coil for signal transmission and a flexible four-channel surface coil for signal reception. Five different $\mathrm{T} 1 \rho$-weighted data sets ( spin-lock times $[\mathrm{TSL}]=12,18,25,35$, and $45 \mathrm{~ms}$ ) were acquired in a sagittal oblique plane using a standard turbo spin echo sequence combined with a spin-lock preparation module $[20,25]$ with the following parameters: spin-lock amplitude $\left(\mathrm{B}_{1}\right)=400 \mathrm{~Hz}$, repetition time $=274 \mathrm{~ms}$, echo time $=13 \mathrm{~ms}$, field of view $=18 \times 18 \mathrm{~cm}^{2}$, matrix $=384 \times$ 384 , in-plane resolution $=0.46 \times 0.46 \mathrm{~mm}^{2}$, number of slices $=22$, slice thickness $=3 \mathrm{~mm}$, number of averages $=$ 1 , and total scan time $=21$ minutes.

The data sets were postprocessed using custom programs written in MATLAB (MathWorks Inc, Natick, MA, USA). Three-millimeter thick slices, starting from the lateral rim of the acetabular sourcil and progressing medially, were selected from the first (TSL $=12 \mathrm{~ms}$ ) T1 $\rho$-weighted data set (Fig. 1A). T1 $\rho$ relaxation maps were calculated by fitting the T1 $\rho$-weighted images pixelwise to a monoexponential decay function with two unknown parameters $\left(\mathrm{S}_{0}\right.$ and T1 $\rho$ ) using the Levenberg-Marquardt algorithm:

$\mathrm{S}(\mathrm{TSL})=\mathrm{S}_{0} \cdot \exp (-\mathrm{TSL} / \mathrm{T} 1 \rho)$,

where $\mathrm{S}$ is the signal intensity and $\mathrm{S}_{0}$ is the signal intensity at $\mathrm{TSL}=0 \mathrm{~ms}[16]$.

In the second step the cartilage was segmented on the first T1 $\rho$-weighted data set (Fig. 1B). Six $30^{\circ}$ zones in the sagittal plane were defined semiautomatically (Fig. 1C). Subsequently in each hip, a total of six zones in the sagittal pane was analyzed. Depending on the depth of the acetabulum, between six and nine slices of each $3 \mathrm{~mm}$ were segmented in the transverse plane. Therefore, between 36 (six zones in the sagittal plane $\times$ six slices in the transverse plane) and 54 ROIs (six zones $\times$ nine slices) were assessed. 

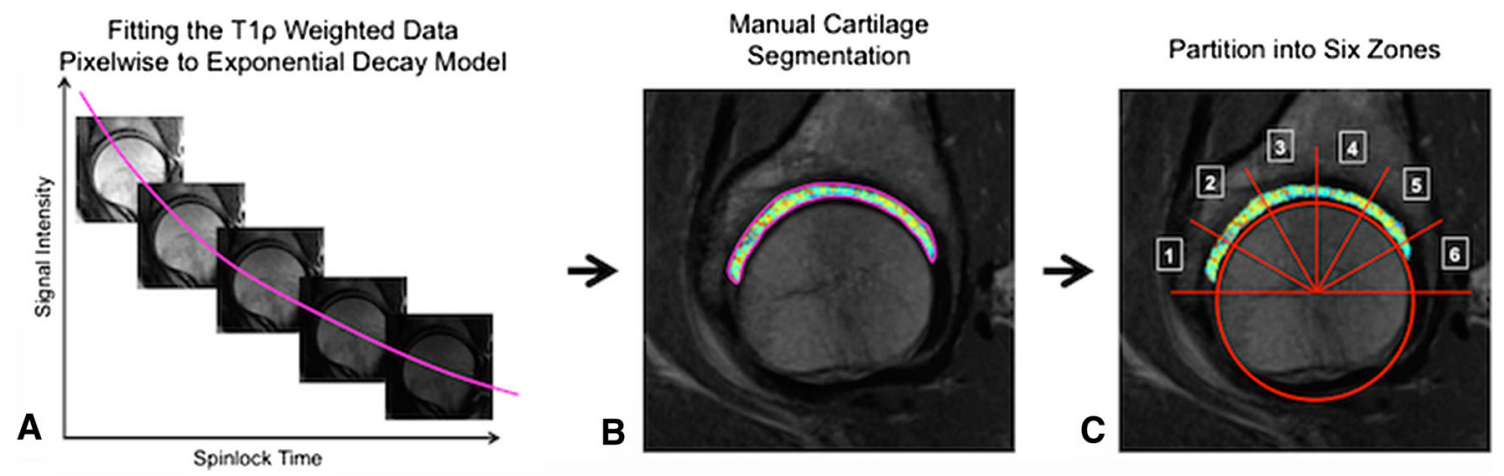

Fig. 1A-C T1 $\rho$ mapping in hip cartilage is demonstrated. T1 $\rho$-weighted data sets (A) were processed using custom programs written in MATLAB. The acetabular and femoral cartilage bilayer was manually segmented (B) and semiautomatically divided into six zones (C).

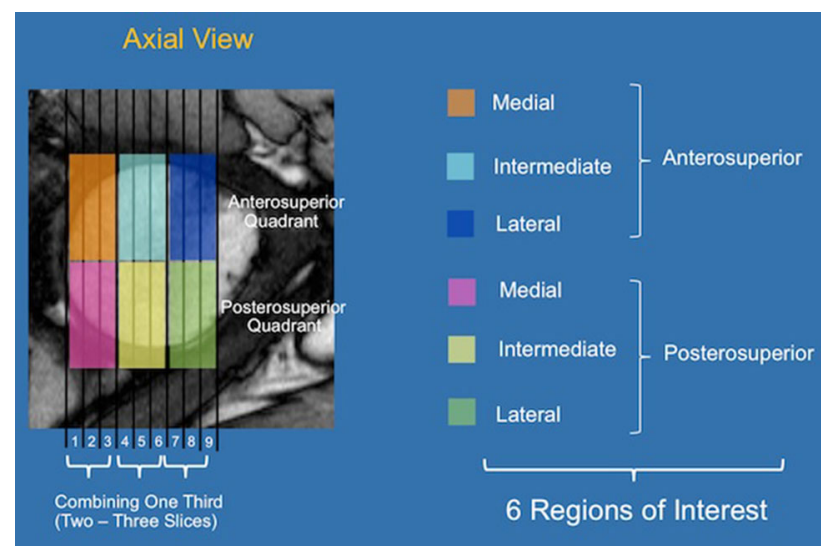

Fig. 2 Six final ROIs in T1 $\rho$ mapping in hip cartilage on an axial slice are shown. The hip cartilage was divided into an anterosuperior and a posterosuperior quadrant and into a lateral, an intermediate, and a medial third. The six colors illustrate the six final ROIs on a axial slice of the hip.

Each ROI contained both the femoral and acetabular cartilage of a $30^{\circ}$ wide interval in the sagittal plane and of a 3$\mathrm{mm}$ thickness in the transverse plane (Fig. 2).

Three different ROI selection methods were analyzed: (Method 1) mean T1 $\rho$ value of the entire hip cartilage; (Method 2) all 36 to 54 ROIs were individually assessed; and (Method 3) six large ROIs were defined.

\section{Method 1}

All ROIs segmented in each hip were added to one ROI representing the femoral and acetabular hip cartilage expanding anterior from 3:00 o'clock position to posterior 9:00 o'clock position and reaching lateral from the acetabular rim to the most medial part of the hip cartilage at the same level in a coronal plane as the 3:00 o'clock and 9:00 o'clock positions. The mean T1 $\rho$ relaxation time of the entire hip cartilage was combined based on the number of pixels within the ROIs.
Method 2

Each of the initially segmented 36 to 54 small ROIs (sections of $30^{\circ}$ wide intervals in the sagittal plane and 3-mm slices in the transverse plane) were compared within the two groups.

\section{Method 3a}

The 36 to 54 small ROIs were collapsed to generate six bigger ROIs. This ROI selection was based on intraoperative and CT-based observations [3, 30] describing the maximal cartilage damage at 1:00 clock position, expanding from 12:00 to 2:00. This led to a division into an anterosuperior and a posterosuperior quadrant. Furthermore, the cartilage damage was described with an average width of one-third of the acetabular depth. This led to a division into lateral, intermediate, and medial thirds. The subsequent six ROIs were: the anterosuperior and posterosuperior quadrants, divided into lateral, intermediate, and medial thirds. Each ROI spans $90^{\circ}$ in the sagittal plane and one-third of the acetabular depth in the transverse plane. To obtain the anterosuperior quadrant, Zones 1 to 3 were combined; to obtain the posterosuperior quadrant, Zones 4 to 6 were combined. The lateral, intermediate, and medial thirds were combined as follows: In hips with six slices, each third included two slices; in hips with seven slices, the two lateral slices represented the lateral third, the three intermediate slices, the intermediate third, and the two medial slices, the medial third. In hips with eight slices, the three lateral slices represented the lateral third, the two intermediate slices the intermediate third, and the three medial slices the medial third. In hips with nine slices, each third contained three slices.

T1 $\rho$ values in each ROI were normalized based on the number of pixels. 


\section{Method 3b}

The ratio of $\mathrm{T} 1 \rho$ values of the anterosuperior over the posterosuperior quadrant was calculated within each third. The relatively spared posterosuperior quadrant was used as an internal control.

To assess interobserver reliability, 10 patients (five in the control group and five in the test group) were analyzed by two observers (HA, GM). For intraobserver reliability, 20 hip MRIs (10 in the control group and 10 in the test group) were analyzed twice by one observer within a time period of 2 weeks (HA). To assess interscan reliability, three patients underwent two scans within a time period of 2 weeks and were analyzed twice by one observer (HA).

\section{Statistical Analysis}

A Kolmogorov-Smirnov test was run to confirm normal distribution. T1 $\rho$ values were compared using independent samples Student's t-test. Interclass correlation coefficient (ICC) and root mean square coefficient of variation (RMS$\mathrm{CV}$ ) were used to analyze intraobserver, interobserver, and interscan reliability. All statistical analyses were performed with the SPSS ${ }^{\circledR}$ statistics software package (Version 22; IBM Corp, Armonk, NY, USA).

\section{Results}

The first study aim was to determine appropriate ROIs for cartilage T1 $\rho$ mapping in hips with a cam deformity. This was done using four methods: 1, 2, 3a, and 3b; results using each of those methods are summarized in sequence here. The second study aim was to assess intra- and interobserver reliability for cartilage $\mathrm{T} 1 \rho$ mapping in hips with a cam deformity; results of those analyses follow the mapping results.

Method 1: Entire Cartilage (all zones and slices combined)

The mean $\mathrm{T} 1 \rho$ value in the entire cartilage in all hips combined was $33 \pm 4 \mathrm{~ms}$ (range, 27-46 ms).

The mean $\mathrm{T} 1 \rho$ value in the entire cartilage in hips with cam deformity (34 $\pm 4 \mathrm{~ms}$ ) was higher than in control hips (31 \pm 3 ms; mean difference: $2.5 ; 95 \%$ confidence interval [CI], 4.7-0.4; $\mathrm{p}=0.019$; Table 3).

\section{Method 2: Analysis of All Small ROIs}

The control hips show a pattern with low $\mathrm{T} 1 \rho$ values in the anterolateral part and high $\mathrm{T} 1 \rho$ values in the posterolateral part (Fig. 3A). This pattern is lost in hips with a cam deformity (Fig. 3B). An increase in T1 $\rho$ values in hips with a cam deformity was found in lateral slices two and three and in anterosuperior zones one to three. Furthermore, there was an increase in $T 1 \rho$ values found in medial slices six to nine, mainly in anterolateral zones one to three but also in posterior zones five and six (Table 4; Fig. 3C).

Table 3. T1 $\rho$ relaxation times in cartilage in hips with and without cam deformity

\begin{tabular}{lccc}
\hline Region of interest & Cam deformity group & Control-group & p value \\
\hline Entire cartilage & $34 \pm 4(28-46)$ & $32 \pm 3(27-37)$ & $0.019^{*}$ \\
Anterosuperior quadrant & $33 \pm 5(24-45)$ & $29 \pm 4(22-36)$ & $0.039^{*}$ \\
Lateral & $33 \pm 5(23-44)$ & $31 \pm 4(24-36)$ & 0.150 \\
Intermediate & $37 \pm 6(23-50)$ & $33 \pm 4(26-39)$ & $0.014^{*}$ \\
Medial & $33 \pm 4(27-41)$ & $33 \pm 4(24-39)$ & $32 \pm 7(24-40)$ \\
Posterosuperior quadrant & $33 \pm 4(26-48)$ & $31 \pm 4(21-37)$ & 0.660 \\
Lateral & $34 \pm 6(20-52)$ & $0.90 \pm 0.15(0.65-1.24)$ \\
Intermediate & $1.00 \pm 0.12(0.77-1.33)$ & $1.01 \pm 0.17(0.76-1.51)$ \\
Medial & $1.01 \pm 0.14(0.64-1.31)$ & $1.06 \pm 0.13(0.89-1.35)$ \\
Ratio anterosuperior to posterosuperior & $0.039^{*}$ \\
Lateral & $1.08 \pm 0.17(0.71-1.69)$ & $0.018^{*}$ \\
Intermediate & & & 0.950 \\
Medial & & & 0.678 \\
\hline
\end{tabular}

Values are mean $\pm \mathrm{SD}$ with ranges in parentheses; $*$ significant difference between hips with and without a cam deformity; T1 $\rho$ values in the entire hip cartilage in the anterosuperior and posterosuperior quadrants are in milliseconds; the quadrants are further divided in lateral, intermediate, and medial thirds. 
Fig. 3A-C T1 $\rho$ mapping of cartilage in hips with and without cam morphology showing the difference between the two groups using the original 54 ROIs. The figure illustrates T1 $\rho$ values of cartilage in control hips (A), in hips with cam morphology (B), and the difference between the two groups (C) with a gray-coded scale. The nine rings illustrate slices one to nine (lateral to medial). The six wedges illustrate Zones 1 to 6 (anterior to posterior). The bar on the right side decodes the gray scale to the $\mathrm{T} 1 \rho$ values (in $\mathrm{ms}$ ) or to the difference (in percentage) between hips with and without cam morphology.

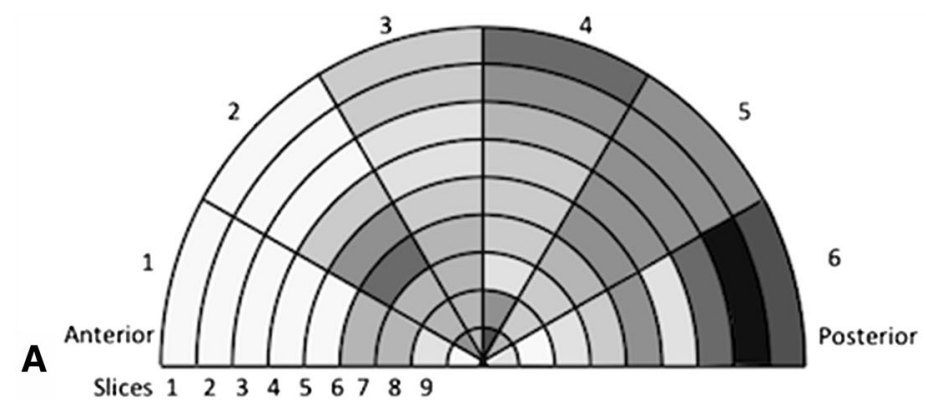

Slices $\begin{array}{lllllllllll}1 & 2 & 3 & 4 & 5 & 6 & 7 & 8 & 9\end{array}$

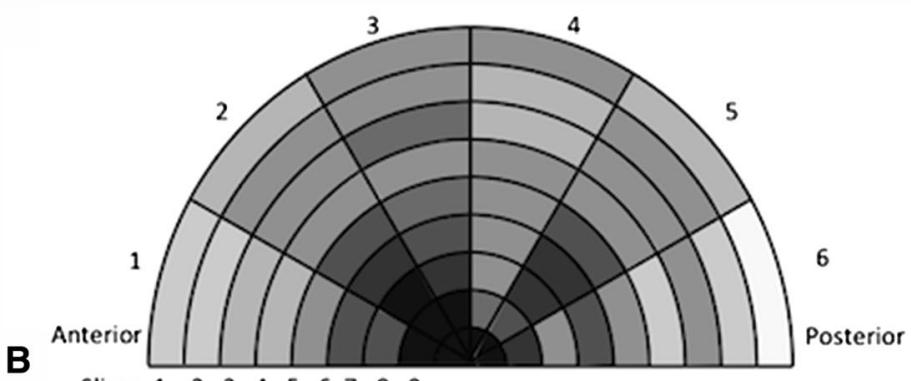

Slices $1 \begin{array}{lllllllll} & 2 & 3 & 4 & 5 & 6 & 7 & 8 & 9\end{array}$

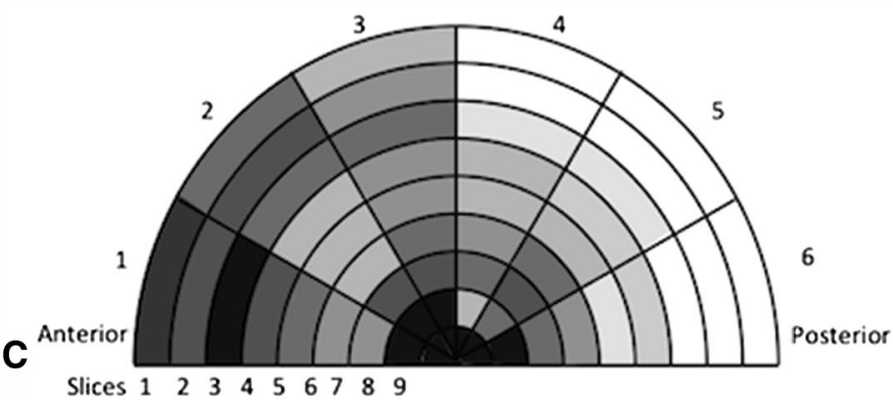

Method 3a: Six Large ROIs

Control hips showed a pattern with low T1 $\rho$ values in the lateral third of the anterosuperior quadrant $(29 \pm 4 \mathrm{~ms})$ and moderate T1 $\rho$ values in the remaining five ROIs (between 31 and $33 \mathrm{~ms}$ ) (Fig. 4A). Hips with a cam deformity showed a pattern with high T1 $\rho$ values in the medial third of the anterosuperior quadrant $(37 \pm 6 \mathrm{~ms})$ and moderate T1 $\rho$ values in the remaining five ROIs (between 32 and 34 ms) (Fig. 4B). Subsequently, comparing hips with and without a cam deformity, T1 $\rho$ values were increased in the lateral and medial thirds in the anterosuperior quadrant (mean: $32.3 \pm 4.9 \mathrm{~ms}$ versus $29.4 \pm 4.1 \mathrm{~ms}$; mean difference: $3.0 ; 95 \%$ CI, $5.8-0.2 ; \mathrm{p}=0.039$ and mean $36.5 \pm$ $5.6 \mathrm{~ms}$ versus $32.6 \pm 3.8 \mathrm{~ms}$; mean difference: $3.8 ; 95 \%$ CI, 6.9-0.8; $\mathrm{p}=0.014)$ and in the medial third in the posterosuperior quadrant (mean: $34.4 \pm 5.5 \mathrm{~ms}$ versus 31.1 $\pm 3.9 \mathrm{~ms}$; mean difference: 3.1 ; $95 \% \mathrm{CI}, 6.2-0.1 ; \mathrm{p}=$ 0.039) (Table 3; Fig. 4C).
Method 3b: Ratio Analysis

The ratio of the anterosuperior to the posterosuperior quadrant was increased in the lateral third (mean: $1.00 \pm$ 0.12 versus $0.90 \pm 0.15$; mean difference: $0.10 ; 95 \% \mathrm{CI}$, $0.18-0.2 ; p=0.018$ ), but not in the intermediate and medial thirds in hips with a cam deformity compared with control hips (Table 3).

Intraobserver, Interobserver, and Inter-MR Scan Assessment

The T1 $\rho$ mapping and analysis protocol resulted in strong intraobserver, interobserver, and inter-MR scan reliability. ICC and RMS-CV were $0.965(\mathrm{p}<0.001)$ and $4 \%$ (intraobserver), $0.953(\mathrm{p}<0.001)$ and $4 \%$ (interobserver), and $0.988(\mathrm{p}<0.001)$ and $9 \%$ (inter-MR scan), respectively. 


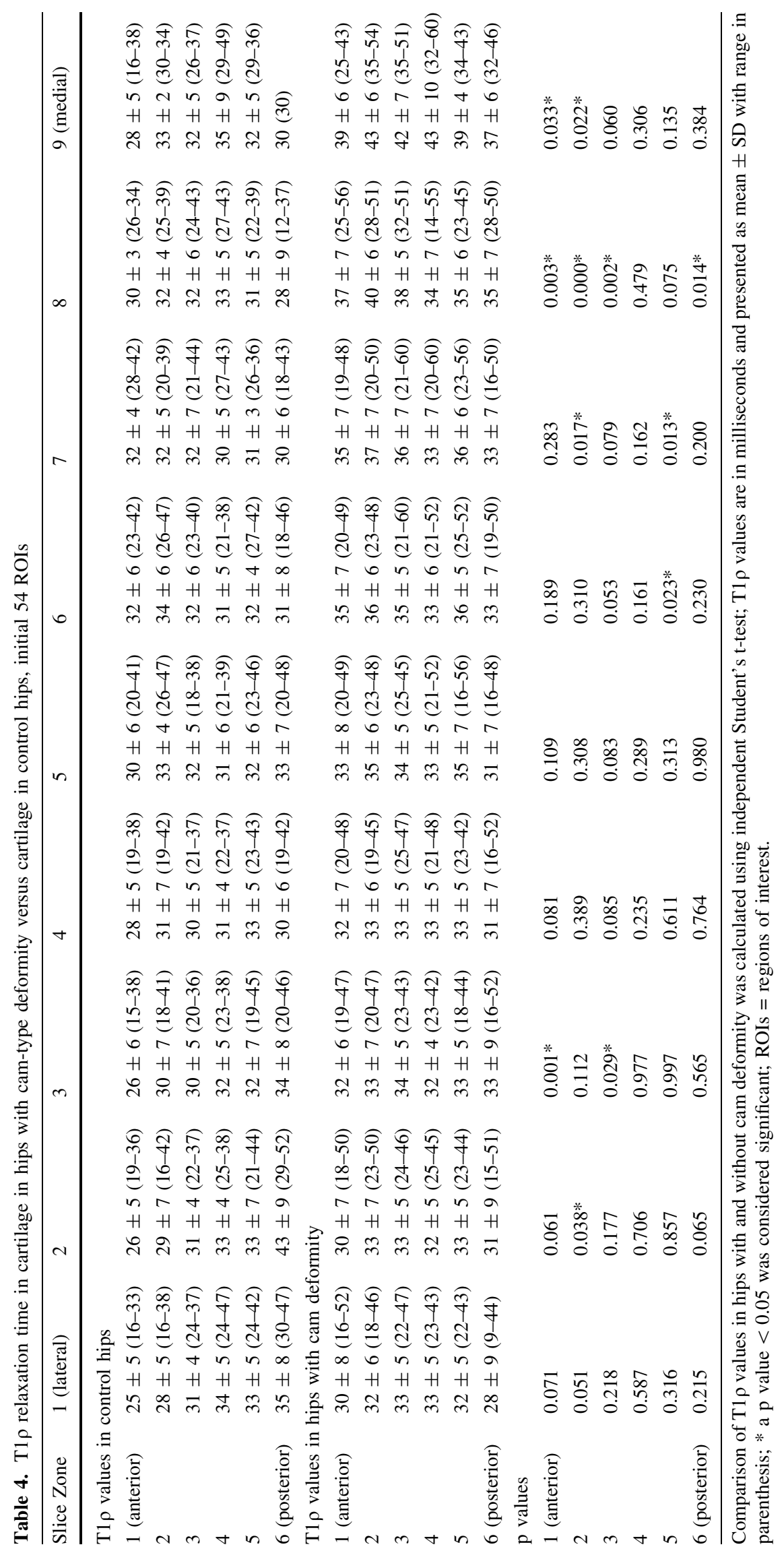


Fig. 4A-C T1 $\rho$ mapping of cartilage in hips with and without cam morphology showing the difference between the two groups using the final six ROIs. The figure illustrates $\mathrm{T} 1 \rho$ values of cartilage using the final six ROIs in control hips (A), in hips with cam morphology (B), and the difference between the two groups (C) with a gray-coded scale. The hip cartilage was divided into an anterosuperior and posterosuperior quadrant and in the lateral (lat), intermediate (int), and the medial (med) thirds. The bar on the right side decodes the gray scale to the $\mathrm{T} 1 \rho$ values (in $\mathrm{ms}$ ) or to the difference (in percentage) between hips with and without cam morphology.
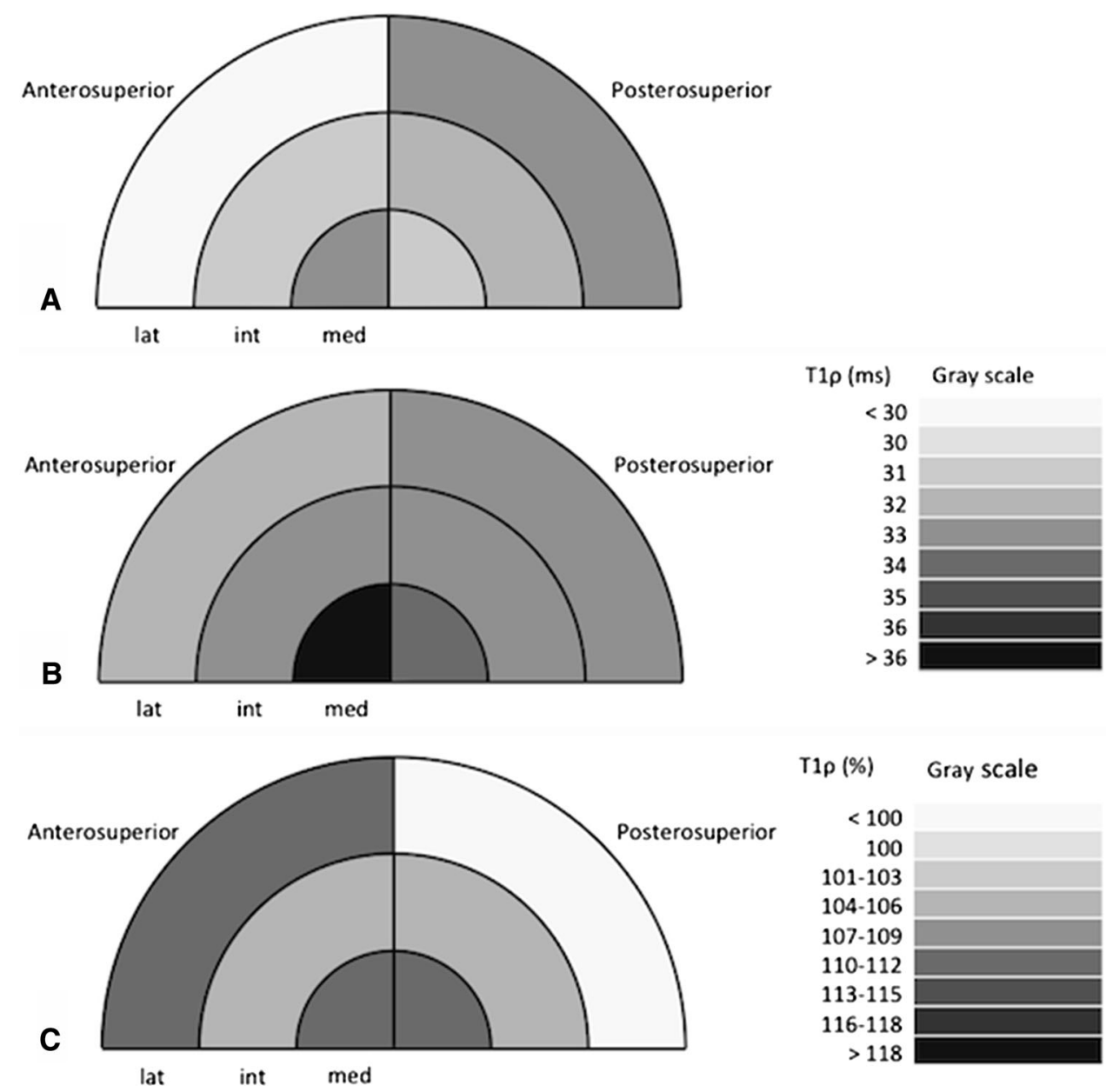

\section{Discussion}

Radiography and standard MRI are unable to assess earlystage, microscopic cartilage damage before macroscopic damage occurs. Over the last several years, numerous imaging modalities such as T1 $\rho$, T2, dGEMRIC, diffusionweighted imaging, sodium imaging, and gagCEST MRI have evolved [18]. These techniques have been applied mostly to the knee, because the hip has always represented a greater challenge as a result of its anatomic features (ie, sphericity).

The aims of this study were to determine representative ROIs for cartilage T1 $\rho$ mapping in hips with a cam deformity and to assess intra- and interobserver reliability for cartilage T1 $\rho$ mapping in hips with a cam deformity. The six ROIs (Method 3) were based on described intraoperative findings and showed a difference of T1 $\rho$ values in this study between hips with and without a cam deformity and are recommended for further studies analyzing T1 $\rho$ MRI in cartilage in hips with a cam deformity. Strong inter-, intraobserver, and inter-MR scan reliability was found for $\mathrm{T} 1 \rho$ imaging and analysis of the hip cartilage at $1.5 \mathrm{~T}$.
A limitation of the study is that femoral cartilage and acetabular cartilage were assessed as a combined bilayer. With the spatial resolution used in the study, it was not possible to confidently distinguish between the two layers. We suspect that some patients with a cam deformity and advanced cartilage damage have falsely low $\mathrm{T} 1 \rho$ values as a result of loss of acetabular cartilage; subsequently, the $\mathrm{T} 1 \rho$ values in these hips predominantly reflect the cartilage status of the remaining cartilage on the femoral head, which is less exposed to damage in hips with cam deformity. Having said that, Subburaj et al. [29], using 3-T MRI, showed that despite using $3 \mathrm{~T}$, the bilayer technique is actually more reproducible than the single-layer acetabular cartilage and equal to a femoral head cartilage single layer.

In this study, our first method analyzed $T 1 \rho$ values in the entire hip cartilage and the second $\mathrm{T} 1 \rho$ values were divided into 36 to 54 ROIs, depending on the size of the hip. Each ROI contained the femoral and acetabular cartilage, a $30^{\circ}$ wide interval in the sagittal plane and was 3 $\mathrm{mm}$ thick in the transverse plane. In control hips, a distinctive pattern with low $\mathrm{T} 1 \rho$ values in the anterolateral 
part has been previously been reported [25]. In comparison, hips with a cam deformity showed increased T1 $\rho$ values mainly in ROIs in the lateral and medial slices in Zones 1 to 3 .

Our second method, the assessment of 36 to 54 individual ROIs, was based on the number of available slices. This partition led to increased spatial information, but also to a large number of ROIs, which makes a comparison, especially between different hip sizes, difficult. Subsequently, we strategically collapsed the original small ROIs to six larger and distinct ROIs, reflecting the known anatomic regions of the hip preferentially damaged in cam FAI seen at surgery [3] mainly in the lateral third of the cartilage and in the anterosuperior quadrant. The difference in the 36 to 54 ROIs was mainly seen in the lateral third of the anterosuperior quadrant and in the medial third (more in the anterosuperior than in the posterosuperior quadrant). When collapsing this into six ROIs, prolonged $\mathrm{T} 1 \rho$ relaxation time was found in the lateral and medial thirds of the anterosuperior quadrant, consistent with the pathomechanism of cam FAI. The same areas showed a difference in T1 $\rho$ values by using the method with 36 to 54 ROIs or the method with six ROIs. Subsequently, it can be said that collapsing the ROIs does not lead to a loss of significance with the added advantage of not being influenced by the size of the hip. The ratio between the anterosuperior and the posterosuperior quadrants was used to eliminate intrinsic interpatient variability. Similar ratios using uninvolved hip cartilage as an intrinsic control have been proposed previously $[15,19,24]$. A difference was found in the ratio in the lateral third, the area exposed to the impingement.

Increased $T 1 \rho$ values in the entire hip cartilage and particularly in the anterosuperior area were consistent with the findings published by Subburaj et al. [29]. Mamisch et al. [17], who used dGEMRIC in hips and described decreased $\mathrm{T} 1$ values in hips with cam-type deformity in the entire cartilage but especially in the anterosuperior quadrant, indicated loss of proteoglycan mainly in this region. Interestingly, the $\mathrm{T} 1 \rho$ prolongation was not only found in the lateral third of the anterosuperior cartilage, where the cam impingement occurs and the cartilage damage is expected, but also in the medial third in both the anterosuperior and posterosuperior quadrants. This indicates the degeneration of the cartilage occurs in areas without direct impingement by the cam deformity.

The T1 $\rho$ mapping and analysis protocol developed and used in this study resulted in high intra- and interobserver ICC and low RMS-CV. Similar findings were published in other studies analyzing $\mathrm{T} 1 \rho$ in the hip cartilage $[5,29]$ indicating strong intra- and interobserver reliability.

Cartilage T1 $\rho$ MRI mapping in hips is feasible at $1.5 \mathrm{~T}$. The six ROIs (Method 3) have been shown feasible to assess cartilage damage in hips with a cam deformity using
T1 $\rho$ MRI. We suggest applying this ROI selection for further studies using quantitative MRI for assessment of cartilage damage in hips with a cam deformity to achieve better comparability and reproducibility between different studies. The application of this ROI selection on hips with other deformities (eg, pincer deformity, developmental dysplasia of the hip, and acetabular retroversion) has to be analyzed and potentially adapted.

\section{References}

1. Barton C, Salineros MJ, Rakhra KS, Beaulé PE. Validity of the alpha angle measurement on plain radiographs in the evaluation of cam-type femoroacetabular impingement. Clin Orthop Relat Res. 2011;469:464-469.

2. Beaulé PE, Hynes K, Parker G, Kemp KA. Can the alpha angle assessment of cam impingement predict acetabular cartilage delamination? Clin Orthop Relat Res. 2012;470:3361-3367.

3. Beck M, Kalhor M, Leunig M, Ganz R. Hip morphology influences the pattern of damage to the acetabular cartilage: femoroacetabular impingement as a cause of early osteoarthritis of the hip. J Bone Joint Surg Br. 2005;87:1012-1018.

4. Bittersohl B, Steppacher S, Haamberg T, Kim YJ, Werlen S, Beck M, Siebenrock KA, Mamisch TC. Cartilage damage in femoroacetabular impingement (FAI): preliminary results on comparison of standard diagnostic vs delayed gadolinium-enhanced magnetic resonance imaging of cartilage (dGEMRIC). Osteoarthritis Cartilage. 2009;17:1297-1306.

5. Carballido-Gamio J, Link TM, Li X, Han ET, Krug R, Ries MD, Majumdar S. Feasibility and reproducibility of relaxometry, morphometric, and geometrical measurements of the hip joint with magnetic resonance imaging at 3T. J Magn Reson Imaging. 2008;28:227-235.

6. Dijkgraaf LC, de Bont LG, Boering G, Liem RS. The structure, biochemistry, and metabolism of osteoarthritic cartilage: a review of the literature. J Oral Maxillofac Surg. 1995;53:1182-1192.

7. Domayer SE, Mamisch TC, Kress I, Chan J, Kim YJ. Radial dGEMRIC in developmental dysplasia of the hip and in femoroacetabular impingement: preliminary results. Osteoarthritis Cartilage. 2010;18:1421-1428.

8. Felson DT, Hodgson R. Identifying and treating pre-clinical and early osteoarthritis. Rheum Dis Clin North Am. 2014;40:699-710.

9. Ferro FP, Ho CP, Dornan GJ, Surowiec RK, Philippon MJ. Comparison of $\mathrm{T} 2$ values in the lateral and medial portions of the weight-bearing cartilage of the hip for patients with symptomatic femoroacetabular impingement and asymptomatic volunteers. Arthroscopy. 2015;31:1497-1506.

10. Ganz R, Parvizi J, Beck M, Leunig M, Nötzli H, Siebenrock KA. Femoroacetabular impingement: a cause for osteoarthritis of the hip. Clin Orthop Relat Res. 2003;417:112-120.

11. Gupta R, Viravavanich W, Kuo D, Su F, Link T, Ma B, Li X. MR $\mathrm{T}(1)$ rho quantifiction of cartilage focal lesions in acutely injured knees: correlation with arthroscopic evaluation. Magn Reson Imaging. 2014;32:1290-1296.

12. Hack K, Di Primio G, Rakhra K, Beaulé PE. Prevalence of camtype femoroacetabular impingement morphology in asymptomatic volunteers. J Bone Joint Surg Am. 2010;92:2436-2444.

13. Hirose J, Nishioka H, Okamoto N, Oniki Y, Nakamura E, Yamashita Y, Usuku K, Mizuta H. Articular cartilage lesions increase early cartilage degeneration in knees treated by anterior cruciate ligament reconstruction: T1rho mapping evaluation and 1-year follow-up. Am J Sports Med. 2013;41:2353-2361. 
14. Johnston TL, Schenker ML, Briggs KK, Philippon MJ. Relationship between offset angle alpha and hip chondral injury in femoroacetabular impingement. Arthroscopy. 2008;24:669-675.

15. Lattanzi R, Petchprapa C, Glaser C, Dunham K, Mikheev AV, Krigel A, Mamisch TC, Kim YJ, Rusinek H, Recht M. A new method to analyze dGEMRIC measurements in femoroacetabular impingement: preliminary validation against arthroscopic findings. Osteoarthritis Cartilage. 2012;20:1127-1133.

16. Li X, Benjamin Ma C, Link TM, Castillo DD, Blumenkrantz G, Lozano J, Carballido-Gamio J, Ries M, Majumdar S. In vivo $\mathrm{T}$ (1rho) and $\mathrm{T}(2)$ mapping of articular cartilage in osteoarthritis of the knee using $3 \mathrm{~T}$ MRI. Osteoarthritis Cartilage. 2007;15:789-797.

17. Mamisch TC, Kain MS, Bittersohl B, Apprich S, Werlen S, Beck M, Siebenrock KA. Delayed gadolinium-enhanced magnetic resonance imaging of cartilage (dGEMRIC) in Femoacetabular impingement. J Orthop Res. 2011;29:1305-1311.

18. Matzat SJ, van Tiel J, Gold GE, Oei EH. Quantitative MRI techniques of cartilage composition. Quant Imaging Med Surg. 2013;3:162-174.

19. McGuffin WS, Melkus G, Rakhra KS, Beaule PE. Is the contralateral hip at risk in patients with unilateral symptomatic cam femoroacetabular impingement? A quantitative T1rho MRI study. Osteoarthritis Cartilage. 2015;23:1337-1342.

20. Nepple JJ, Carlisle JC, Nunley RM, Clohisy JC. Clinical and radiographic predictors of intra-articular hip disease in arthroscopy. Am J Sports Med. 2011;39:296-303.

21. Okazaki K, Takayama Y, Osaki K, Matsuo Y, Mizu-Uchi H, Hamai S, Honda H, Iwamoto Y. Subclinical cartilage degeneration in young athletes with posterior cruciate ligament injuries detected with $\mathrm{T} 1 \rho$ magnetic resonance imaging mapping. Knee Surg Sports Traumatol Arthrosc. 2015;23:3094-3100.

22. Palmer A, Pollard T, McNally E, Wilson D, Carr A, Glyn-Jones S. Delayed gadolinium-enhanced MRI of cartilage (dGEMRIC) predicts the pattern of hip osteoarthritis progression at five-year follow-up. Arthroscopy. 2013;29.

23. Peers SC, Maerz T, Baker EA, Shetty A, Xia Y, Puwal S, Marcantonio D, Keyes D, Guettler J. T1 $\rho$ magnetic resonance imaging for detection of early cartilage changes in knees of asymptomatic collegiate female impact and nonimpact athletes. Clin J Sport Med. 2014;24:218-225.

24. Pollard TC, McNally EG, Wilson DC, Wilson DR, Mädler B, Watson M, Gill HS, Carr AJ. Localized cartilage assessment with three-dimensional dGEMRIC in asymptomatic hips with normal morphology and cam deformity. J Bone Joint Surg Am. 2010;92:2557-2569.

25. Rakhra KS, Cárdenas-Blanco A, Melkus G, Schweitzer ME, Cameron IG, Beaulé PE. Is the T1 $\rho$ MRI profile of hyaline cartilage in the normal hip uniform? Clin Orthop Relat Res. 2015;473:1325-1332.

26. Rakhra KS, Lattanzio PJ, Cardenas-Blanco A, Cameron IG, Beaule PE. Can T1-rho MRI detect acetabular cartilage degeneration in femoroacetabular impingement? A pilot study. $J$ Bone Joint Surg Br. 2012;94:1187-1192.

27. Regatte RR, Akella SV, Lonner JH, Kneeland JB, Reddy R. T1rho relaxation mapping in human osteoarthritis (OA) cartilage: comparison of T1rho with T2. J Magn Reson Imaging. 2006;23:547-553.

28. Steppacher SD, Anwander H, Zurmühle CA, Tannast M, Siebenrock KA. Eighty percent of patients with surgical hip dislocation for femoroacetabular impingement have a good clinical result without osteoarthritis progression at 10 years. Clin Orthop Relat Res. 2015;473:1333-1341.

29. Subburaj K, Valentinitsch A, Dillon AB, Joseph GB, Li X, Link TM, Vail TP, Majumdar S. Regional variations in MR relaxation of hip joint cartilage in subjects with and without femoralacetabular impingement. Magn Reson Imaging. 2013;31:11291136.

30. Tannast M, Goricki D, Beck M, Murphy SB, Siebenrock KA. Hip damage occurs at the zone of femoroacetabular impingement. Clin Orthop Relat Res. 2008;466:273-280.

31. Wheaton AJ, Casey FL, Gougoutas AJ, Dodge GR, Borthakur A, Lonner JH, Schumacher HR, Reddy R. Correlation of T1rho with fixed charge density in cartilage. J Magn Reson Imaging. 2004;20:519-525. 